\title{
Modelling the effect of continuous mixer operating parameters on mixture quality
}

\author{
Alexey Kaliganov ${ }^{1}$, Vladimir Konovalov ${ }^{2} *$, Alexey Chupshev ${ }^{l}$ and Vyacheslav \\ Teryushkov $^{l}$ \\ ${ }^{1}$ Faculty of Engineering, Penza State Agrarian University, 30 Botanicheskaya St., Penza, Russia, \\ 440014 \\ ${ }^{2}$ Department of Machine Building Technology, Penza State Technological University, 1A/11, Proezd \\ Baydukova / Gagarina St., Penza, Russia, 440039
}

\begin{abstract}
The aim of the research was to obtain a regression model of the influence of some structural and kinematic parameters of a continuous mixer working element on the quality of the prepared mixture. The research methodology included the analysis of the design of the mixing unit and the identification of factors that could significantly affect the quality of the mixture. Later, on the basis of the experimental studies, the quality of the mixture at given values of factors was determined and a regression model was established. The developed functional diagram of a continuous mixing unit made it possible to establish factors that most intensively affected the quality of the prepared mixture. The obtained adequate regression model of the coefficient of variation of the content of the control component in the samples of the mixture indicated an improvement in the quality of the mixture with an increase in the frequency of rotation of the mixers and the number of the arms levels. In terms of quality indicators, a rotation frequency of about $1500 \mathrm{rpm}$ was most preferable with a number of mixer levels of at least 5 .
\end{abstract}

\section{Introduction}

In modern society, composites and mixtures are widely used in industry and construction. For the preparation of these mixtures, mixers of different designs and with different working elements are used. Drum mixers with a rotating container $[1,2,3]$ prepare mixtures with low energy consumption, but in this case it is problematic to achieve high uniformity of the mixture. Mixers with a screw working element $[4,5,6]$ are more energyconsuming, but can produce better mixtures. High-speed and low-speed circulation mixers $[7,8]$ are applicable for liquids, but problematic for bulk mixtures. Paddle-type mixers require more energy, but they evenly distribute the components throughout the volume of the mixture $[9,10]$.

Regardless of the design of the mixing device, the designers are trying to ensure high quality of the mixture with a short mixing time and low energy costs $[11,12,13]$. This is ensured by both the design and kinematic parameters of the mixers, and the technological

${ }^{*}$ Corresponding author: konovalov-penza@,rambler.ru 
conditions for their use. A significant effect is observed with multistage mixing of the components. The use of continuous mixing units significantly reduces the energy consumption of mixture formation, however, increases the requirements for accuracy and uniformity of component supply [11,13].

The aim of the research was to obtain a regression model of the influence of some structural and kinematic parameters of a continuous mixer on the quality of the prepared mixture.

\section{Methods and Materials}

The research methodology included the analysis of the design of the mixing unit and the identification of factors that could significantly affect the quality of the mixture. Later, on the basis of the experimental studies, the quality of the mixture at given values of factors was determined and a regression model was established.

To improve the distribution of additional components in the dry mixture, multistage mixing of the components was used. Initially, as a result of the interaction of the sprayed streams of the feed components, a primary mixture is obtained, which is further mixed in the second main stage.

The mixing unit consists of two component feed systems (additive feeders), and a mixing system (Figure 1,2), the components feed systems into the hopper 1 for additives, under which a multicomponent drum (paddle) dispenser 2 with adjusting flaps 3 is placed. The dispenser paddles provide the supply of a specific additive with the required capacity and its continuous spray at the outlet of the dispenser opening. The feed system of the main component (mixture filler) consists of a hopper 8 with a spiral conveyor 7 mounted on the shaft 6 . Radial beaters 5 with a net 4 are installed in the discharge zone. The mixing system includes a preliminary mixing chamber 9 and main mixing chamber 16 . The operation of these devices in high-speed mode not only provides spraying of feeds, but also helps to increase the uniformity of the supply of the mixture components. Inside the main mixing chamber (in the mixer housing) there installed a shaft with several levels of paddle mixers 13 located on it and an unloading hole blocked by a gate valve 14 .

During the experiments with the mixer, the rotational speed of the working body $(\mathrm{n}=$ $\left.750 ; 1000 ; 1500 \mathrm{~min}^{-1}\right)$ and the number of levels of six-blade mixers $(\mathrm{Zr}=1 ; 3 ; 5$ pcs.) located on the central vertical shaft were changed. The performance of the mixer corresponded to $1.6 \mathrm{~kg} / \mathrm{s}$ with a bulk density of the mixture of $620 \mathrm{~kg} / \mathrm{m} 3$. When these parameters changed, their influence on the mixture non-uniformity $v$ was studied (coefficient of variation of the proportion of the control component in the samples, $0.01 \%$ ). The proportion of the control component in the experiments was $8 \%$. The experiments were repeated three times. The number of samples to determine the coefficient of variation was 20. The mass of one sample was $100 \mathrm{~g}$. 


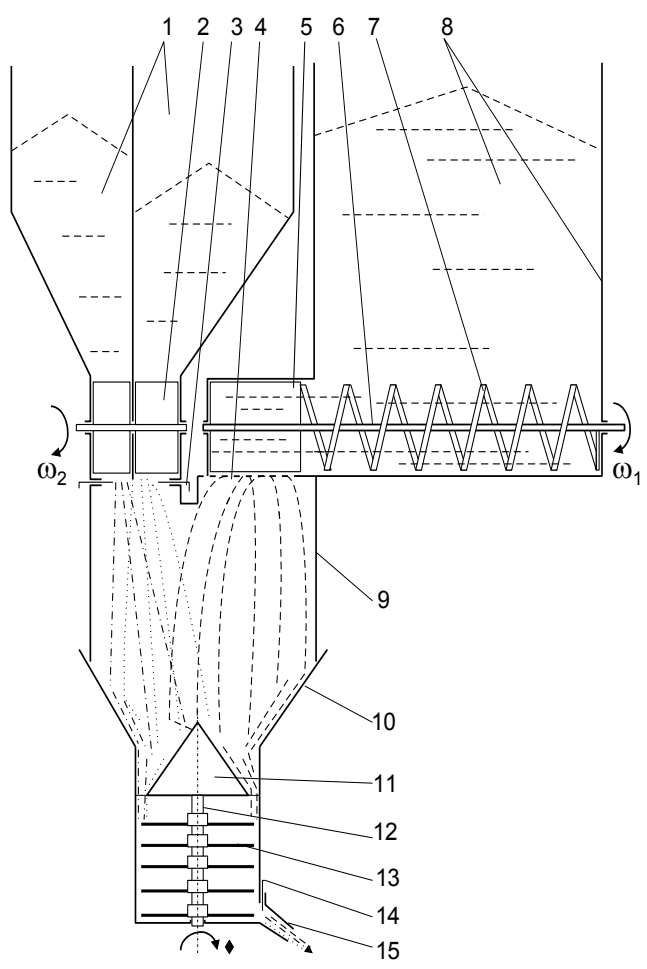

Figure 1. Structural and technological scheme of the mixing unit for supplying additives to dry feed: 1 and 8 - additives and filler hoppers; 2- drum (paddle) multisection dispenser (rotated); 3 - adjusting flap for supplying additives; 4 - discharge opening net of filler supply; 5 - beater with blades; 6 feeder shaft; 7 - spiral conveyor; 9 - pre-mixing chamber; 10 - guide funnel; 11 - distribution cone; 12 - mixer shaft; 13 - mixer paddles; 14 - gate valve; 15 - unloading tray; 16 - mixer housing (main mixing chamber)

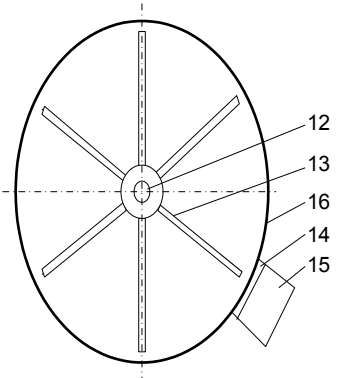

Figure 2. Scheme of the mixing unit for supplying additives to dry feed (a top view of the main mixing chamber): 12 - mixer shaft; 13 - mixer paddles; 14 - gate valve; 15 - unloading tray

\section{The Results of the Studies}

The main evaluation criteria of the functional scheme of the proposed mixing unit are (Figure 3): productivity (mass supply) of dispensers /Y0i-1, Y1i-1/, as well as of the mixing device as a summing value of all dispensers; the proportion of components in the mixture /Y21, Y31/ and the unevenness of mixing as a coefficient of variation /Y23, Y33/ for a component with a smaller fraction in the mixture in the first and second mixing stages. 
Considering that the mixture can be used only if its quality is high, this indicator is the main one.

The analysis of the functional diagram showed that the parameters of the dispensers affect the formulation of the mixture, and the quality of the mixture is not significantly affected. The turbulence of mixing and the duration of exposure have a strong influence. In the abovementioned device, these effects are determined by the speed of rotation of the working unit and the number of levels of paddle mixers. The design parameters of the used mixers were substantiated in the works $[13,14]$.

An analysis of the correlation of these factors and the quality of the mixture showed the absence of a direct linear dependence (Figure 4). The studied independent factors did not correlate with each other. After processing the obtained experimental data on the quality of the mixture, the dependence of the non-uniformity of the mixture $v(\%)$ on the studied parameters was obtained (Figure 5):

$$
v=1-e^{\left[-36.4 \cdot\left(-4.47+7.77 \cdot \mathrm{Zr}^{-0.0334}+20.688 \cdot n^{-0.486}\right)\right]},
$$

where $\mathrm{Zr}$ - the number of levels of paddle mixers, units; $\mathrm{n}$ - agitator speed, $\min ^{-1}$. At that, the Pearson correlation coefficient is $\mathrm{R}=0.97378$.

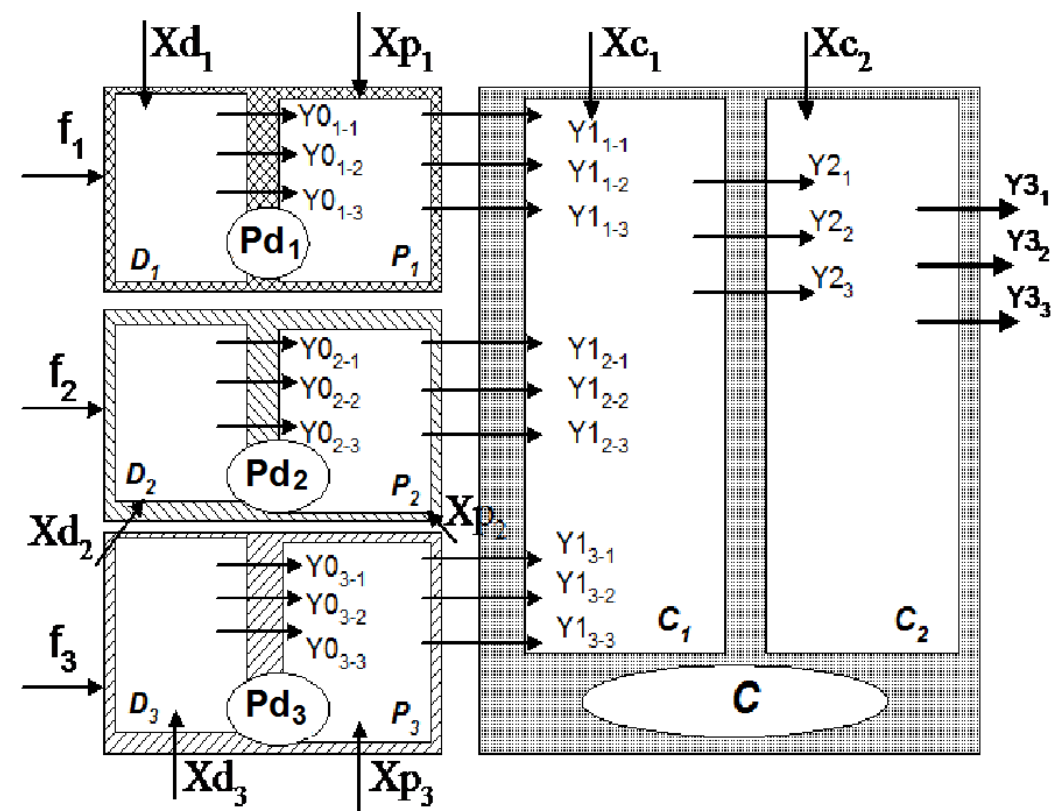

Figure 3. Functional diagram of a mixing unit for adding additives to bulk materials: $P_{d_{1}}, P_{d_{2}}$, $P_{d_{3}}$ - bulk filler and additive feeders; D1, D2, D3, P1, P2, P3 - dispensers and sprayers of the corresponding components of the mixture; $\mathrm{C}, \mathrm{C} 1, \mathrm{C} 2$ - a mixing system including a mixer of preliminary $\mathrm{C} 1$ and main $\mathrm{C} 2$ mixing; $\mathrm{f} 1, \mathrm{f} 2, \mathrm{f} 3$ - generalized statistical indicators characterizing the particle size distribution of the components of the mixture supplied to the dosing, their physical and mechanical properties; $\mathrm{Xd} 1, \mathrm{Xd} 2, \mathrm{Xd} 3$ - generalized values of the internal factors of the components dosing devices; Xp1, Xp2, Xp3 - generalized values of the internal factors of the components spraying devices; Xc1, Xc2 - generalized values of the internal factors of the mixing devices of the preliminary and main mixing; Y0i-1, Y0i-2, Y0i-3 - productivity (mass supply) of the i-th component fed to mixing; deviation from the set flow rate; uneven feed; Y1i-1, Y1i-2, Y1i-3 - mass feed, flight path of the material flow, particle size distribution of particles, etc .; Y21, Y22, Y23, Y31, Y32, Y33 the proportion of the component in the mixture, the deviation of the proportion of components from the recipe, the quality of the mixture (uneven mixing/coefficient of variation/) of the mixing devices of the preliminary and main mixing. 


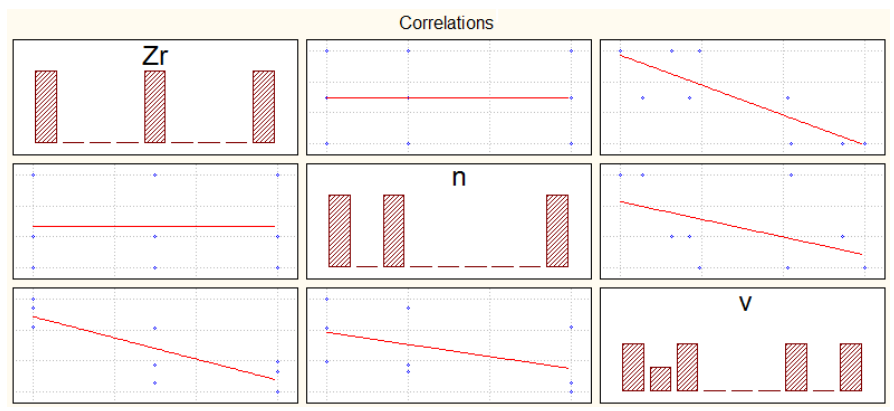

Figure 4. Correlation of factors $\mathrm{Zr}$ (number of levels of mixers) and $\mathrm{n}$ (their rotation speed) on the coefficient of variation $v$ of the content of the control component in the samples

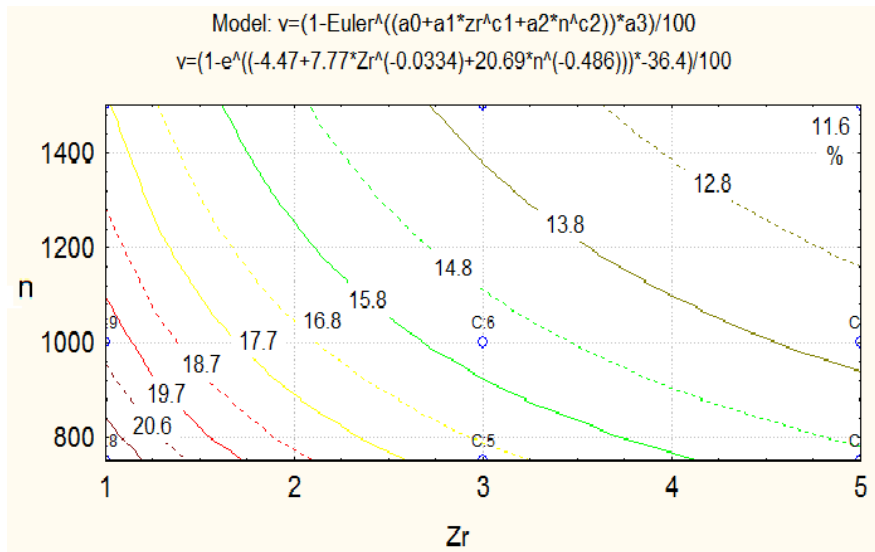

Figure 5. The results of statistical processing of the data on the influence of factors $\mathrm{Zr}$ (number of levels of the mixers) and $n$ (their rotation speed) on the coefficient of variation $v$ of the content of the control component in the samples

Comparing the calculated values of the regression model (Figure 6) with the experimental results, we can see their good accordance. The residues unaccounted by the model (Figure 7) are random in nature.

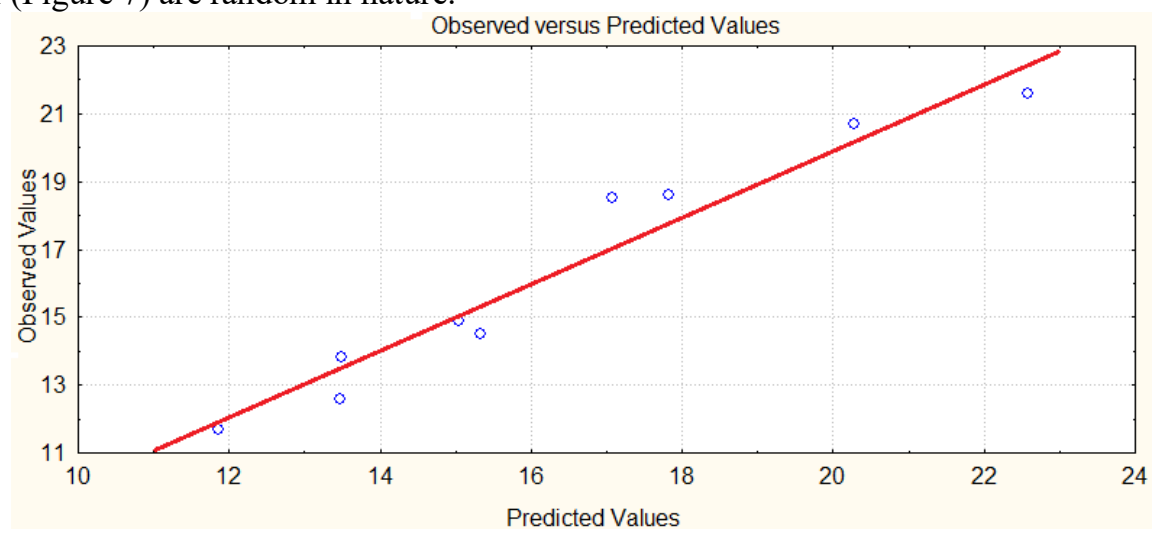

Figure 6. Compliance of the calculated values with the experimental data

An analysis of the graph of the obtained regression model (Figure 5) indicates an improvement in the quality of the mixture with an increase in both the frequency of rotation of the mixers and the number of levels of the paddles. In terms of quality indicators, the 
rotation frequency of about $1500 \mathrm{rpm}$ is most preferable with the number of levels of the mixers of not less than 5 . The indicated rotation frequency of the mixers corresponds to the frequency of rotation of the electric motors, which makes it possible to use coaxial arrangement of the shafts of the electric motor and the mixers. This reduces energy loss. However, additional studies are required to justify the working area of the mixing unit by the interval of the fraction of the smaller component in the mixture.

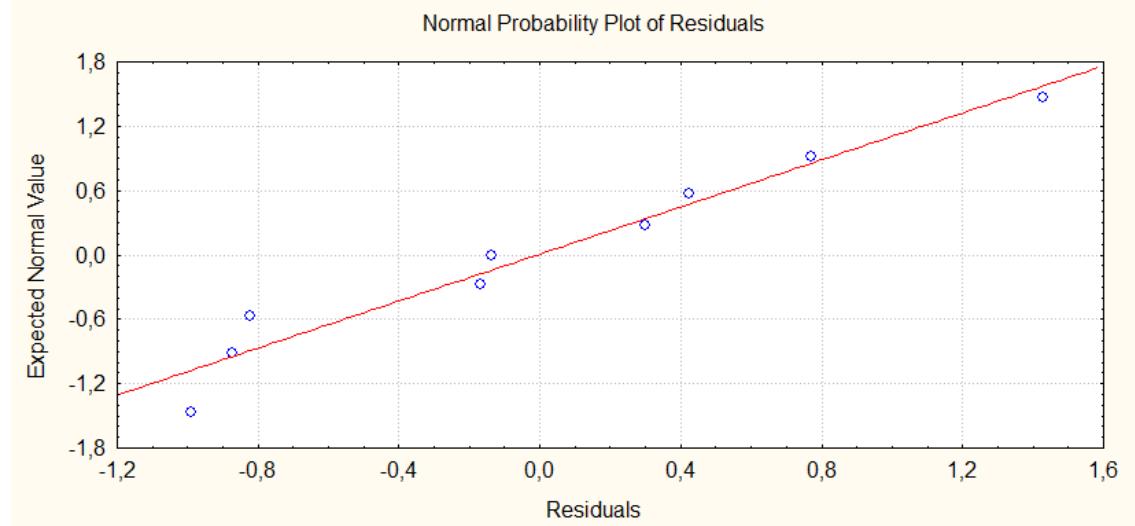

Figure 7. Distribution of residues unaccounted by the regression model.

\section{Conclusion}

The developed functional diagram of a continuous mixer made it possible to establish factors that most intensively affect the quality of the prepared mixture. The obtained adequate regression model of the coefficient of variation of the content of the control component in the samples of the mixture indicates an improvement in the quality of the mixture with an increase in the frequency of rotation of the mixers and the number of the levels of the paddles. In terms of quality indicators, the rotation speed of about $1500 \mathrm{rpm}$ is most preferable with the number of levels of the mixers of not less than 5. Additional studies are required to justify the working area of the mixing unit by the interval of the fraction of the smaller component in the mixture.

\section{References}

1. L. Li, D. Wang, C. Li, D. Jiang and Z. Ping. Design and Experimental Optimization of Combined-type Ration Mixer of Drum and Blade. Nongye Jixie Xuebao Transactions of the Chinese Society for Agricultural Machinery 48(10) 67 (2017) https://DOI: 10.6041/j.issn.1000-1298.2017.10.008

2. V. Teruchcov, A. Cupschev, V. Konovalov and Yu. Rodionov Modeling and force analysis of drum devices based on the geometry of the material segment IOP Conf. Series: Journal of Physics: Conf. Series 1278012012 (2019) doi:10.1088/17426596/1278/1/012012

3. I. Emeljanova, A. Anishchenko and O. Dobrohodova. Means to enhance operating efficiency of the means to enhance operating efficiency of the concrete mixer trucks with the purpose of highly-homogeneous concrete mix. Preparation Int. J. of Eng. and Technol. 7/3 102 (2018) https://DOI: 10.14419/ijet.v7i3.2.14383

4. K.V. Vyakaranam, B.K. Ashokan and J.L. Kokini. Evaluation of effect of paddle element stagger angle on the local velocity profiles in a twin-screw continuous mixer 
with viscous flow using Finite Element Method simulations. Journal of Food Engineering $\quad \mathbf{1 0 8 ( 4 ) ,} \quad$ pp. $\quad 585-599 \quad$ (2012) https://doi.org/10.1016/j.jfoodeng.2010.12.001

5. O. Celik and C. Bonten. A novel experimental setup for characterization of polymer blends in single-screw extruders. AIP Conference Proceedings 2055, 020008 (2019) https://doi.org/10.1063/1.5084809

6. J.P. Kearns Ingredient consideration, preparation of feeds, selection of extrusion equipment and automatic controls for extrusion of pet and aquatic feeds Int. Symp. on Animal and Aquaculture Feedstuffs by Extrusion Technology/Int. Seminar on Advanced Extrusion Technology in Food Applications (Sao Paulo, Brazil) (1998)

7. C. Habchi, A. Ghanem, T. Lemenand, D. Della Valle, and H. Peerhossaini. Mixing performance in Split-And-Recombine Milli-Static Mixers - A numerical analysis Chemical Engineering Research and Design pp. 298-306 https://doi.org/10.1016/j.cherd.2018.12.010

8. S. Soni, L. Sharma, P. Meena, S. Roy and K.D.P. Nigam. Compact coiled flow inverter for process intensification Chemical Engineering Science 193, 312-324 (2019) https://doi.org/10.1016/j.ces.2018.09.008

9. A. Yaraghi, M. Ebrahimi, F. Ein-Mozaffari and A. Lohi. Mixing assessment of noncohesive particles in a paddle mixer through experiments and discrete element method (DEM) Advanced Powder Technology 29(11), pp. 2693-2706 (2018) https://doi.org/10.1016/j.apt.2018.07.019

10. M. Ebrahimi, A. Yaraghi, F. Ein-Mozaffari and A. Lohi. The effect of impeller configurations on particle mixing in an agitated paddle mixer Powder Technology 332, pp. 158-170 (2018) https://doi.org/10.1016/j.powtec.2018.03.061

11. A. Chupshev, V. Konovalov and M. Fomina Optimization in work modeling of a mixer IOP Conf. Series: Journal of Physics: Conference Series 1084012010 (2018) doi :10.1088/1742-6596/1084/1/012010

12. A. Chupshev, V. Teryushkov, V. Konovalov, A. Mishanin, V. Novikov and M. Fomina. Functional model of energy consumption for mixing with a vertical paddle mixer IOP Conf. Series: Earth and Environmental Science 403012102 (2019) doi:10.1088/1755-1315/403/1/012102

13. A.V. Chupshev, V.V. Konovalov and S.S. Petrova. Optimization of mixer parameters to minimize mixing energy consumption. Bulletin of Samara State Agricultural Academy. 3. pp.72-76. (2009)

14. A.V. Chupshev, V.V. Konovalov and V.P. Teryushkov. Influence of blade diameter and number on mixture unevenness and mixing power consumption. Vestnik of federal state educational establishment of higher professional education "Moscow state agroengineering university named after V.P. Goryachkin". 2 (27). pp. 132-133. (2008) 